\title{
Perfil sociodemográfico e profissional dos enfermeiros da atenção básica à saúde de Cuiabá - Mato Grosso
}

\author{
Sociodemographic and professional profile of primary health care nurses in Cuiabá - Mato Grosso
}

\section{Perfil sociodemográfico y profesional de enfermeros de atención básica de salud de Cuiabá - Mato Grosso}

Áurea Christina Paula Corrêa ${ }^{1}$, Emerson Francisco de Araújo ${ }^{2}$, Antônio César Ribeiro ${ }^{3}$ Inês de Cássia Franco Pedrosa ${ }^{4}$

\section{RESUMO}

Estudo descritivo de abordagem quantitativa e delineamento transversal que objetivou traçar o perfil sociodemográfico e profissional dos enfermeiros da rede básica de saúde de Cuiabá-MT. Compuseram a amostra 79 enfermeiros das Unidades Básicas do município que responderam um instrumento fechado de coleta de dados com a contemplação de aspectos relacionados ao perfil do sujeito-enfermeiro. A análise dos dados possibilitou concluir que: $88,6 \%$ são do sexo feminino; a maioria encontra-se na faixa etária dos 26 aos 30 anos (26,6\%); 57\% nasceram em Mato Grosso; 49,4\% estão casados e 32,9\% pertencem à classe econômica B1; graduados há menos de cinco anos correspondem a 48,1\%; 73,4\% possuem curso de pósgraduação lato sensu e $0 \%$ realizou curso stricto sensu; 88,6\% participaram de capacitações/atualizações com carga horária superior a 40 horas nos últimos cinco anos. Quanto ao vínculo empregatício, 58,2\% submetiam-se a contratos temporários. 0 estudo aponta para a necessidade de investimentos no trabalho e na educação continuada para sanar a situação precária.

Descritores: Atenção Básica à Saúde; Enfermagem em Saúde Comunitária; Recursos Humanos de Enfermagem.

\section{ABSTRACT}

This descriptive study was performed using a quantitative approach and cross-sectional design with the objective of outlining the sociodemographic and professional profiles of the primary health care nurses in Cuiabá-Mato Grosso. The sample consisted of 79 nurses working in Basic Health Units in the referred city, who answered a closed data collection instrument addressing aspects related to the profile of the nurse-subject. The data analysis permitted the conclusion that $88.6 \%$ are women; most are aged between 26 and 30 years (26.6\%); 57\% were born in Mato Grosso; $49.4 \%$ are married, and $32.9 \%$ belonged to social class B1; $48.1 \%$ had graduated within the last five years; $73.4 \%$ had a lato sensu graduate degree, and none attended a stricto sensu course. Of all the participants, $88.6 \%$ participated in training/update programs with a course load of at least 40 hours over the last five years. Regarding employment, 58.2\% were working under a temporary contract. The study points at the need for investments to reduce the precariousness of employment and to support continuing education.

Descriptors: Primary Health Care; Community Health Nursing; Nursing Staff.

\section{RESUMEN}

Estudio descriptivo, cuantitativo, transversal, que objetivó trazar perfil sociodemográfico y profesional de enfermeros de red básica de salud de Cuiabá-MT. Muestra compuesta por 79 enfermeros de Unidades Básicas municipales, que respondieron un instrumento cerrado de recolección de datos, contemplando aspectos relativos al perfil del sujeto-enfermero. El análisis de los datos permitió determinar que $88,6 \%$ son de sexo femenino; la mayoría en faja etaria de 26 a 30 años (26,6\%) nació en Mato Grosso; $49,4 \%$ casados, 32,9\% pertenecen a la clase económica B1; 48,1\% graduados hace menos de cinco años, $73,4 \%$ con curso de posgraduación lato sensu, ninguno realizó curso stricto sensu; 88,6\% participó de capacitaciones/actualizaciones con carga horaria superior a 40 horas en los últimos cinco años. Respecto al vínculo laboral, $58,2 \%$ trabajaba bajo contrato temporario. El estudio orienta a la necesidad de inversiones para mejorar la precaria calidad del vínculo laboral y la capacitación permanente.

Descriptores: Atención Primaria de Salud; Enfermería en Salud Comunitaria; Personal de Enfermería.

\footnotetext{
1 Enfermeira, Doutora em Enfermagem, Professora Adjunto II, Faculdade de Enfermagem (FAEN), Universidade Federal de Mato Grosso (UFMT). Cuiabá, MT, Brasil. E-mail: aureaufmt@gmail.com.

${ }^{2}$ Acadêmico do curso de Graduação em Enfermagem, FAEN, UFMT. Cuiabá, MT, Brasil. E-mail: emersonfaraujo@uol.com.br.

${ }^{3}$ Enfermeiro, Doutor em Enfermagem, Professora Adjunto I, FAEN, UFMT. Cuiabá, MT, Brasil. E-mail: anceri@terra.com.br.

${ }^{4}$ Enfermeira, Discente do Programa de Pós-Graduação em Enfermagem - nível Mestrado, FAEN, UFMT. Enfermeira da Secretaria de Estado da Saúde de Mato Grosso. Cuiabá, MT, Brasil. E-mail: inespedrosa@hotmail.com.
} 


\section{INTRODUÇÃO}

O presente artigo relata os resultados de uma pesquisa que teve como objeto de estudo o perfil dos enfermeiros da atenção básica à saúde do município de Cuiabá, Mato Grosso, desenvolvida em função da importância que esse espaço de intervenção à saúde tem no contexto do Sistema Único de Saúde (SUS).

Neste estudo, consideram-se os termos Atenção Primária à Saúde (APS) e Atenção Básica à Saúde (AB) como sinônimos, ambos se referindo aos serviços de saúde operacionalizados na esfera municipal, em nível local(1).

Essa distinção é necessária para que o conceito de Atenção Básica seja compreendido não como "medicina dos pobres", que oferece cuidados simplificados e de baixo custo, que se apresenta como uma compensação social com a finalidade de mascarar as desigualdades sociais ${ }^{(2)}$, mas como um conjunto de ações de saúde, no âmbito individual e coletivo, que abrangem ações de promoção e proteção da saúde, de prevenção de agravos, de diagnóstico e tratamento, de reabilitação e de manutenção da saúde ${ }^{(3)}$.

Tais ações são desenvolvidas por meio do exercício de práticas gerenciais e sanitárias democráticas e participativas, sob forma de trabalho em equipe, dirigidas a populações de territórios bem delimitados, pelas quais assume a responsabilidade sanitária, considerando a dinamicidade da região em que vivem essas populações. Utilizando tecnologias de elevada complexidade e baixa densidade, com o propósito de resolver os problemas de saúde de maior frequência e relevância da localidade ${ }^{(3)}$.

$A \quad A B$ ou $A P S$, no bojo da proposta do SUS, é concebida como porta de entrada preferencial dos usuários para o sistema de saúde, possibilitando o acesso universal e contínuo a serviços de qualidade e resolutivos, orientada pelos princípios da universalidade, da acessibilidade e da coordenação do cuidado, do vínculo e continuidade, da integralidade, da responsabilização, da humanização, da equidade e da participação social ${ }^{(3)}$.

A implantação da $A B$ como estratégia de reorganização da atenção à saúde tem relevância inquestionável, uma vez que já existem evidências suficientes que os países cujos sistemas de saúde se organizaram a partir dos princípios da atenção primária, alcançaram melhores resultados em saúde, menores custos, maior satisfação do usuário e maior equidade, mesmo em situações de grande desigualdade social, como é o caso do Brasil( ${ }^{(4)}$.

Contudo, o sucesso na implementação de políticas no âmbito da saúde depende, em especial, do perfil dos seus recursos humanos, uma vez que respondem pelo desenvolvimento concreto de ações que podem qualificar o novo modelo de assistência à saúde proposto com a implantação do SUS, de maneira a possibilitar sua vigência no cotidiano dos serviços de saúde, nesse sentido é unânime o reconhecimento da importância de se criar um - novo modo de fazer saúde ${ }^{(5)}$, o que requer profissionais com características específicas para atuação sob uma nova racionalidade.

Neste sentido, no nível da $A B$, a qualidade do trabalho e do trabalhador de enfermagem concorrem entre os principais fatores para a garantia da sua melhor execução e, para tanto, o enfermeiro deve assumir o papel de protagonista central neste processo de trabalho. Assim, considera-se que o perfil do trabalhador da saúde, especificamente o enfermeiro, relaciona-se, sobretudo, à finalidade impressa ao processo de trabalho em saúde ${ }^{(6)}$, sendo que esses atores podem imprimir a esse processo direções determinadas pelo âmbito técnico, ético e político, uma vez que esses profissionais devem ser capazes de planejar, organizar, desenvolver e avaliar ações que respondam às necessidades em saúde da comunidade, na articulação com os diversos setores envolvidos na promoção da saúde.

O sucesso da implementação de qualquer proposta no âmbito da saúde depende, em especial, do perfil dos atores envolvidos, sobretudo os profissionais, pois, o perfil dos recursos humanos em saúde deve alterar-se na medida em que uma das maiores dificuldades na consolidação da $A B$ diz respeito à carência de profissionais, considerando que devem atender os requisitos para atuarem nesse novo modelo de atenção à saúde ${ }^{(7)}$.

A proposta ideológica e organizacional do SUS requer trabalhadores generalistas atuando em enfermagem na $A B$, com formação orientada por novos arranjos de poderes e saberes, de maneira a contribuírem com o estabelecimento de novos contornos para o trabalho em saúde e enfermagem neste contexto, considerando a proposição de oferecer a população atenção integral à sua saúde ${ }^{(6)}$. 
Dessa forma, faz-se necessário que o gestor da $A B$ repense o perfil necessário para o enfermeiro de maneira a garantir a manutenção dos valores, da missão e da visão da rede primária de atenção à saúde, tendo como horizonte o alcance das metas estabelecidas. É fundamental que o profissional atuante seja ágil em decisões, criativo, inovador, capaz de agregar valor econômico e social a suas ações, somado ao potencial para resolução de problemas e a preocupação constante de se manter atualizado para acompanhar as inovações ${ }^{(8)}$.

Neste contexto, a enfermagem deve ser concebida como prática social, melhor dizendo, como trabalho que precisa ser compreendido com vistas a sua inserção em determinado contexto e relacionado a outros trabalhos, como uma prática que conforma e é conformada no contexto sócio-histórico onde é produzida ${ }^{(6)}$.

Assim, o estabelecimento do perfil do enfermeiro requer o entendimento de que toda pessoa tem direito à assistência de enfermagem adequada, considerando o ser humano em sua totalidade e em constante interação com o meio ambiente. Para além, é preciso considerar o enfermeiro como sujeito atuante em diversos campos de ação e em vários níveis de atenção à saúde, o que exige dele permanente atualização( ${ }^{(8-9)}$, configurando-se, na $A B$, como presença sine qua non, uma vez que pode ser considerado elemento chave para o sucesso da reorganização de todo o setor saúde.

É preciso reconhecer a importância e a necessidade da abordagem do perfil de recursos humanos em saúde, em especial do enfermeiro, por esse profissional ter compromisso ético "com o desenvolvimento de uma prática de enfermagem que busque desenvolver intervenções no cotidiano com possibilidades de operar os serviços de saúde de forma a estabelecer uma relação diferenciada do trabalhador de saúde/usuário, relação acolhedora; marcada pelo compromisso e responsabilização pela saúde dos usuários. Também, pela preocupação com o desenvolvimento da autonomia do usuário, visando que este vá se apropriando de diversas tecnologias, que cada vez mais resolva ou minimize parte daquilo que the tem causado sofrimento"(6).

Reconhecendo a importância da proposição da efetivação do trabalho em equipe, neste modelo assistencial, no contexto do SUS, é importante ressaltar que, "um rol de atividades e funções, buscando definir um perfil mínimo para atuação, não é suficiente para um trabalho em saúde compartilhado, humanizado, com responsabilização e vínculo com a comunidade, reconhecendo a saúde como direito de cidadania. Quando consideramos que a unidade produtora dos serviços de saúde não é um profissional isoladamente, mas sim a equipe; que o foco central de atenção não é o indivíduo exclusivamente, mas a família e seu entorno; que as intervenções necessárias para proporcionar o cuidado à saúde devem se sustentar no conhecimento que contemple as determinações bio-psico-sociais da saúde-doença e cuidado, e na autonomia e responsabilização dos profissionais com os usuários, famílias e comunidade; a assistência à saúde passa a ter a característica central de um trabalho coletivo e complexo, em que a interdisciplinaridade, bem como a multiprofissionalidade são necessárias"(10).

É preciso considerar, também, as características pessoais, humanas e de formação dos enfermeiros que atuam na $A B$, no contexto do trabalho em equipe, para se obter informações mais abrangentes sobre os serviços prestados à comunidade nesse nível de atenção. Dessa forma, faz-se necessário identificar o perfil desses profissionais que integram o corpo de recursos humanos dos serviços de saúde para, se necessário, elaborar e adotar medidas que visem à melhoria das atividades desenvolvidas para atender de forma condizente as necessidades da população(11).

Frente ao exposto, emergiu a motivação da realização do presente trabalho, considerando a importância do enfermeiro enquanto membro da equipe de saúde que atua neste nível de atenção, por ser um dos protagonistas do processo de promoção à saúde da população, para além, a inexistência de estudos sobre a temática, especificamente no município, também justifica a sua realização, enquanto forma de contribuir com a qualificação dos profissionais ali atuantes.

Assim, o presente estudo teve como objetivo traçar o perfil sóciodemografico e profissional dos sujeitosenfermeiros da rede de $A B$ à Saúde do município de Cuiabá- Mato Grosso, considerando a importância desse profissional na assistência à saúde na Atenção Primária à Saúde.

\section{METODOLOGIA}

O presente estudo é parte do projeto matricial intitulado "Atuação da enfermagem frente às 
necessidades emergentes na Estratégia Saúde da Família no município de Cuiabá-MT" que vem sendo desenvolvido pelo Grupo de Pesquisa Argos da Faculdade de Enfermagem da Universidade Federal de Mato Grosso (UFMT), financiado pela Fundação de Amparo à Pesquisa de Mato Grosso.

Caracteriza-se como um estudo descritivo com delineamento transversal, desenvolvido nos serviços da rede de $A B$ da Secretaria Municipal de Saúde (SMS) no município de Cuiabá-MT, no período de março a junho de 2010.

O município de Cuiabá, capital do estado de Mato Grosso, segundo o censo realizado no ano de 2010 pelo Instituto Brasileiro de Geografia e Estatística (IBGE, 2011), conta com uma população de 551.350 habitantes. Atualmente a rede de $A B$ do município dispõe de 85 unidades de saúde, sendo 63 Unidades de Saúde da Família (USF) e 22 Centros de Saúde (CS), sendo que três estão localizados na área rural do município. Vale ressaltar que, as unidades das ESF são responsáveis por $43 \%$ de cobertura da população total do município(14), ao passo que $57 \%$ da população estava coberta por unidades básicas do tipo Centro de Saúde.

O município contava à época com 89 enfermeiros que atuavam nas unidades da rede básica, assim distribuídos: 63 nos PSF e 26 nos CS $^{(12)}$. A princípio pretendia-se realizar o presente estudo com a participação de todos os profissionais enfermeiros da rede, no entanto, após a aplicação dos critérios de inclusão - ser enfermeiro e estar lotado em uma das unidades da rede de $A B$ e em pleno exercício das suas funções - a população deste estudo foi reduzida. Para além, foi aplicado o critério de exclusão - excluir aqueles enfermeiros que se encontravam em gozo de férias ou licença. Assim, somados aqueles que não concordaram em participar do estudo, a amostra foi composta por 79 enfermeiros, que representa $88,76 \%$ da população.

Para coleta de dados, inicialmente estabelecia-se contato por telefone com os enfermeiros das unidades para agendar um encontro entre o profissional e o pesquisador, realizando uma rápida explicação da razão do encontro. Vale ressaltar que, inúmeros encontros foram marcados, mas não se concretizaram em função do não comparecimento do enfermeiro ou pela justificativa de estar muito ocupado no momento agendado.
Рага implementação da entrevista em si, o pesquisador inicialmente explicava os objetivos do estudo e o porquê de sua realização. Solicitava sua concordância em participar do estudo e a assinatura do Termo de Consentimento Livre e Esclarecido. Após a assinatura o pesquisador iniciava o preenchimento do instrumento fechado contendo questões objetivas que contemplavam os aspectos relacionados ao perfil do sujeito-enfermeiro, como: caracterização sóciodemográfica, formação profissional, participação política e vínculo profissional.

Após a coleta, os dados foram organizados e digitalizados constituindo um banco de dados com os recursos do software EpiData, versão 3.02. A análise dos dados foi procedida através de análise estatística simples (frequência, média). Para a interpretação dos dados foi considerado o conteúdo do Pacto de Gestão de 2006 do Ministério da Saúde(12), cujo gestor de saúde do município em estudo é signatário e o marco teórico apresentado inicialmente.

O projeto matricial foi submetido à análise pelo Comitê de Ética em Pesquisa do Hospital Universitário Julio Muller, tendo sido aprovado sob Protocolo $N^{\circ}$ 559/CEP-HUJM/08.

\section{RESULTADOS}

\section{Perfil sócio-demográfico}

Рага a caracterização geral do grupo dos enfermeiros da $A B$ de Cuiabá-MT, a pesquisa buscou identificar o sexo, a faixa etária e os aspectos relativos ao estado civil, filhos, chefia da família e a classificação econômica dos participantes.

Dos profissionais pesquisados, a maior parcela $(88,6 \%)$ é do sexo feminino e $11,4 \%$ do sexo masculino. Mato Grosso foi declarado como Unidade da Federação de nascimento por $57 \%$ dos sujeitos e $43 \%$ nasceram em outros estados.

Os enfermeiros da $A B$ são, em sua maioria (26,6\% do total), jovens na faixa etária de 26 a 30 anos, contudo, a segunda concentração mais expressiva ficou na faixa etária de 46 a 50 anos, com 20,2\% do total.

Quanto ao estado civil, 29 (36,7\%) declararam serem solteiros contra $39(49,4 \%)$ que disseram estarem casados. Além disso, outros cinco (6,3\%) informaram conviver com companheiro(a) em união estável; quatro 
$(5,1 \%)$ responderam estar separados judicialmente; e dois $(2,5 \%)$ se declararam viúvos.

Com relação à variável existência de filhos, 46 $(58,2 \%)$ dos entrevistados informaram ter ao menos um filho.

Ao que se refere à variável chefia da família, 46 (62\%) profissionais se auto declararam chefes de suas famílias, outros 16 (20,3\%) apontaram o(a) esposo(a)/companheiro(a) e 11 (13,9\%) declararam os pais como chefes da unidade familiar.
No que diz respeito à classificação econômica, o presente estudo valeu-se do questionário da Associação Brasileira de Empresas de Pesquisa - ABEP, versão 2008, para identificar a classificação econômica dos enfermeiros. Assim, a concentração mais expressiva dos profissionais se deu na classe econômica B1 (32,9\%) e na classe A2 (25,3\%). Além disso, outros $24,1 \%$ ficaram classificados na classe B2, $11,4 \%$ na classe $C$ e apenas 6,3\% na classe A1 (Gráfico 1).

Gráfico 1: Distribuição dos enfermeiros segundo a classe econômica. Cuiabá, MT, 2010.

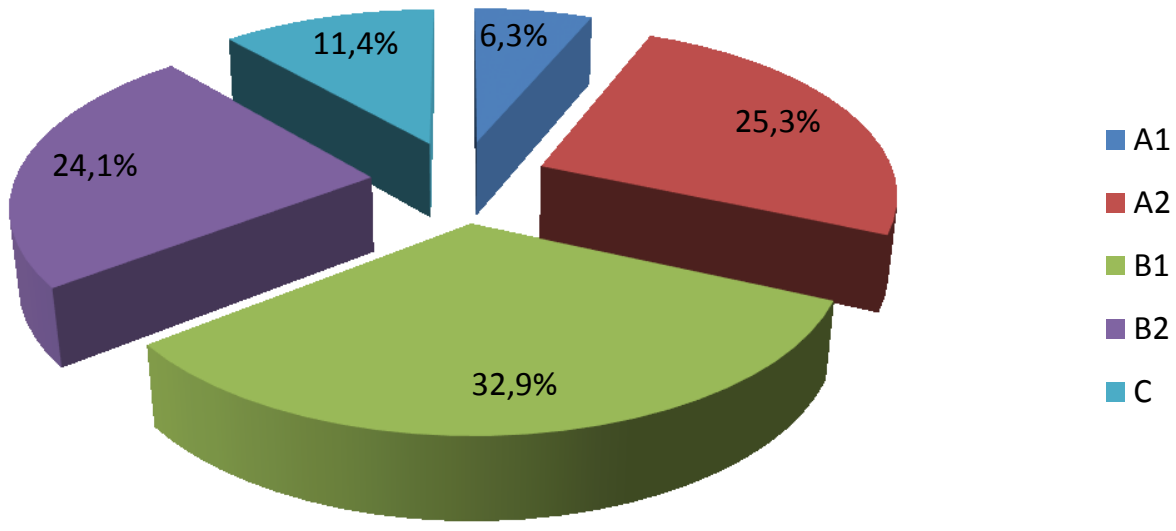

\section{Perfil social, político e cultural}

O presente estudo também buscou identificar o grau de participação política, dos enfermeiros da AB. Isso foi possível através da investigação de três dados: a associação a entidades de caráter técnico-científicocultural na área da saúde e/ou de enfermagem; a filiação a partido político; e a filiação a entidade sindical na área da saúde e/ou na área de enfermagem.

O número de enfermeiros afiliados a partidos políticos foi insignificante, apontada por apenas seis $(7,6 \%)$ profissionais. A filiação a entidade sindical que congrega profissionais da área da saúde foi referida por 11 (13,9\%) enfermeiros, já a filiação ao sindicato da categoria conta com 28 (35,4\%) entrevistados, configurando-se como a participação mais expressiva. Quanto à associação a alguma entidade de caráter técnico-científico-cultural, não houve respostas positivas.

\section{Qualificação profissional dos enfermeiros da Atenção Básica}

Outro elemento investigado para caracterização do enfermeiro da $A B$ de Cuiabá-MT foi a qualificação profissional, constatando que o tempo decorrido desde a conclusão da graduação desses profissionais variou entre menos de cinco anos $(48,1 \%)$ a mais de 25 anos de formado $(15,2 \%)$, demonstrando que a maior parte do corpo de colaboradores enfermeiros é composta por profissionais com pouca experiência na área. A maioria dos enfermeiros $(88,6 \%)$ concluiu a graduação em Mato Grosso, sendo que apenas nove $(11,4 \%)$ profissionais o fizerem nas demais Unidades da Federação (UF) (Gráfico 2). 
Gráfico 2: Proporção dos enfermeiros segundo UF da instituição formadora em nível de graduação em enfermagem. Cuiabá, MT, 2010.

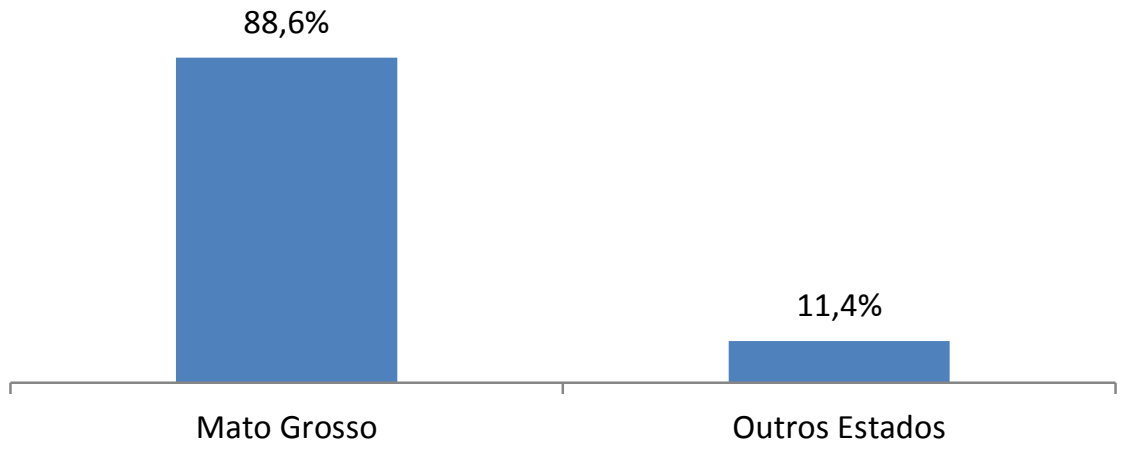

Os dados levantados permitem ainda a reflexão sobre duas questões importantes no processo de formação dos enfermeiros, dada a natureza jurídica das instituições formadoras: a primeira diz respeito ao fato de que 15 (19\%) enfermeiros recorreram a algum tipo de financiamento para custear seus estudos de graduação e, a segunda, relaciona-se à declaração de 31 (39,2\%) dos enfermeiros entrevistados de que mantiveram, durante a graduação, algum tipo de atividade remunerada, o que possibilita inferir que a manutenção dos enfermeiros nas instituições de ensino demandou considerável esforço pessoal e financeiro dos mesmos.
Outro aspecto encontrado que corrobora a posição assumida por Ribeiro ${ }^{(13)}$ está no fato da declaração de 20 (25,3\%) enfermeiros participantes deste estudo terem afirmado ter experiência profissional, na área da saúde, antes da graduação em enfermagem (Gráfico 3). Com relação à iniciativa de buscar aperfeiçoamento profissional através da continuidade dos estudos, uma parcela expressiva dos enfermeiros $(73,4 \%)$ relatou possuir pós-graduação em nível lato sensu. Contudo, nenhum profissional declarou possuir pós-graduação em nível stricto sensu (mestrado e/ou doutorado).

Gráfico 3: Proporção de enfermeiros segundo experiência profissional na area da saúde antes da graduação. Cuiabá, MT, 2010.

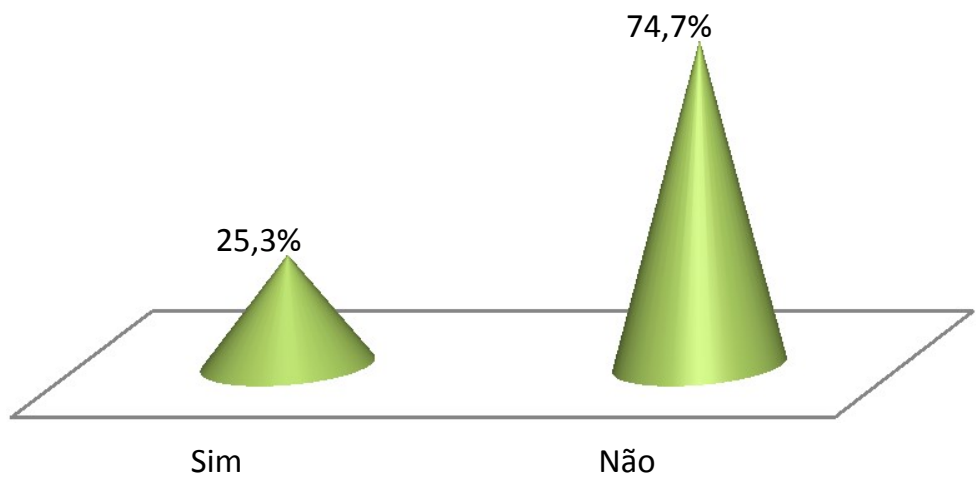

Confirmando a perspectiva da predominância de escolas privadas na região, 41 (70,7\%) enfermeiros informaram ter cursado a especialização em instituições particulares e $45(77,6 \%)$ afirmaram que o curso foi feito em instituições de ensino da região metropolitana de Cuiabá.

Segundo os dados levantados, os cursos de pósgraduação lato sensu mencionados foram agrupados em cinco categorias de acordo com suas abordagens, sendo elas: (I) Gestão e Planejamento em Saúde, que inclui os cursos de gestão e administração em serviços de saúde e enfermagem; (II) Atenção à saúde coletiva, contemplando os cursos de saúde coletiva, saúde da família e suas variações; (III) Atenção à saúde individual, composta pelos cursos voltados para o nível hospitalar; (IV) Atenção individual e coletiva, abordando os cursos que tanto podem ser úteis em nível hospitalar quanto na atenção básica e (V) Docência, que engloba as 
capacitações voltadas para o ensino. Os dados relativos a cursos de especializações realizados pelos enfermeiros do município constam na Tabela 1.

Tabela 1: Distribuição dos enfermeiros da Rede de Atenção Básica segundo curso de especialização realizada. Cuiabá, MT, 2010.

\begin{tabular}{ccc}
\hline $\begin{array}{c}\text { Abordagem Pós-Graduação Latu- } \\
\text { Sensu }\end{array}$ & $\begin{array}{c}\text { Número de Enfermeiros com esta } \\
\text { titulação }\end{array}$ & $\begin{array}{c}\text { Porcentagem de Enfermeiros com esta } \\
\text { titulação }\end{array}$ \\
\hline Atenção à Saúde Coletiva & 44 & $55,9 \%$ \\
Gestão e Planejamento em Saúde & 18 & $22,6 \%$ \\
Atenção à Saúde individual & 11 & $14,3 \%$ \\
Diferentes Cursos & 6 & $\mathbf{7 , 2} \%$ \\
\hline Total & $\mathbf{7 9}$ & $\mathbf{1 0 0 \%}$ \\
\hline
\end{tabular}

Outro aspecto da educação continuada contemplado pelo estudo foi a participação em cursos de capacitação ou atualização com carga horária maior que 40 horas, realizados nos últimos cinco anos, que $88,6 \%$ dos entrevistados declararam ter participado de pelo menos um curso.

A análise da média de cursos de atualização e capacitação com mais de 40 horas, ofertados anualmente, possibilita a constatação de que quase a totalidade dos profissionais não participa de, pelo menos, uma capacitação/ano, pois, 59 (74,7\%) afirmam ter participado de duas capacitações nos últimos cinco anos; 37 (46,8\%) declararam participação em três capacitações; 19 (24\%) dizem ter realizado quatro capacitações e apenas oito $(10,1 \%)$ afirmam ter participado de cinco capacitações com mais de 40 horas. Tal constatação permite considerar que há baixo investimento na educação continuada tanto por iniciativa própria dos servidores quanto por parte dos gestores.

A análise do conjunto das capacitações realizadas pelos enfermeiros demonstra que o percentual mais expressivo deles se atualizou em temáticas como hanseníase $(17,6 \%)$, sala de vacina $(20,2 \%)$ e tuberculose (13,5\%). Tal fato pode estar relacionado ao cumprimento da Política Nacional de Atenção Básica (PNAB) ${ }^{(3)}$ que define como área estratégica para operacionalização da $A B$ a eliminação da hanseníase, o controle da tuberculose, a atenção à saúde da criança, entre outros.

Também foi levantando o percentual de profissionais que assinam periódicos da área da saúde e/ou de enfermagem e dos que participaram de algum evento científico também na área de saúde e/ou de enfermagem nos últimos cinco anos. Da população estudada, oito $(10,1 \%)$ enfermeiros declararam assinar algum periódico na área da saúde. Já na área específica de enfermagem foi observado maior interesse, pois 25 (31,6\%) profissionais afirmaram assinar algum periódico, chamando atenção para o fato de que, dentre esses, $100 \%$ assinam a mesma revista, cuja temática está voltada para a atenção individual curativa.

Por outro lado, a participação em eventos científicos foi expressiva, pois 43 (54,4\%) enfermeiros declararam ter participado de pelo menos um evento na área da saúde nos últimos cinco anos e outros 45 (57\%) afirmaram ter participado de eventos específicos na área de enfermagem. Tal fato pode estar relacionado à constatação de que a maior parte dos enfermeiros se formou há menos de cinco anos, pois é comum a participação em seminários, congressos e outros eventos durante a graduação, ou logo após, рага complementação curricular.

\section{Perfil de vínculo e condições de trabalho}

O presente estudo buscou também caracterizar a natureza do vínculo empregatício dos enfermeiros da $A B$, considerando a forma de acesso e contrato de trabalho.

Dos sujeitos estudados, quase a totalidade $98,7 \%$ declarou ser servidor da Secretaria Municipal de Saúde e apenas 1,3\% profissional informou ser cedido ao serviço municipal pela Secretaria de Estado da Saúde. Apenas $1,3 \%$ sujeito informou possuir vínculo estável, 40,5\% afirmaram ser efetivos e que tiveram acesso ao cargo por meio de concurso público e a grande maioria, 58,2\% dos declarantes, informaram estar submetidos aos contratos de trabalho temporário, o que equivale ao trabalho precário, ou seja, aqueles que exercem suas funções na ausência dos direitos trabalhistas e de proteção social, estando, portanto, desprovidos de normas legais e não garantem os benefícios que dão 
segurança ao trabalhador, tais como: aposentadoria, férias anuais, $13^{\circ}$ salário e licenças remuneradas ${ }^{(14)}$.

\section{DISCUSSÃO}

Com vistas aos dados relativos ao perfil sóciodemográfico dos enfermeiros participantes deste estudo é possível a constatação de que, essa maioria de mulheres/enfermeiras que atua na $A B$ do município também exerce a função de chefe da família, demonstrando a ascensão social que a mulher vem alcançando na sociedade, fato este que se deve a sua entrada no mercado de trabalho, possibilitando-lhe a conquista de espaços e reconhecimento, tanto na esfera pública como na privada.

Os dados levantados também permitem inferir que, o poder aquisitivo familiar dos enfermeiros estudados é relativamente alto, havendo uma parcela significativa enquadrada nas classes B1 e A2, o que pode ser explicado por motivos, como: o fato da maioria ser casada, ocorrendo composição de renda familiar com o/a esposo(a); uma parcela significativa possuir mais de um vínculo empregatício; $41,8 \%$ não ter filhos; dentre outros fatores que podem influenciar diretamente na condição econômica do profissional.

No que diz respeito ao perfil social, político e cultural dos enfermeiros da $A B$ do município observou-se que a participação política e cultural destes profissionais ainda é incipiente, uma vez que, via de regra não são afiliados a partidos políticos, sindicados ou associações/entidades de classe, evidenciando certa despreocupação com questões desse cunho.

Considerando que a PNAB $^{(3)}$ aponta um novo modelo para a reorganização do sistema de saúde brasileiro, modelo este que sofre influência direta de todos os atores envolvidos nos três níveis de governo, espera-se que os profissionais atuantes na área sejam colaboradores participativos quanto aos aspectos políticos, científicos e culturais para, de fato, contribuírem com a efetivação de tal estratégia.

Sendo assim, ao analisar os dados obtidos na presente pesquisa, é possível inferir que estes sujeitos, de maneira geral, não estão engajados em entidades de classe, engajamento esse que favoreceria o desenvolvimento político da categoria, o que, potencialmente, favoreceria o fortalecimento da enfermagem.
No que diz respeito à qualificação profissional dos enfermeiros da Atenção Básica, os dados demonstram que $39,2 \%$ dos enfermeiros mantiveram, durante a graduação, algum tipo de vínculo empregatício, o que pode ter determinado a necessidade de grande esforço pessoal para conclusão do curso.

Estudo recente que refletiu sobre o perfil sóciodemográfico e profissional dos enfermeiros de um hospital público municipal em Cuiabá/MT demonstra o grande número de profissionais com pouco tempo de graduado e o grande percentual de graduados em Mato Grosso, fato que está relacionado à ampliação da oferta de cursos de graduação em enfermagem desde meados da década de 1990 no estado, sobretudo pela iniciativa privada. Atualmente, Cuiabá conta com seis instituições de nível superior que ofertam cursos de graduação em enfermagem, o que traduz incremento considerável no número de vagas ofertadas ${ }^{(13)}$.

A abertura desses cursos pela iniciativa privada possibilita maior acesso a este nível de formação, mas gera a necessidade de grande investimento financeiro, por parte do graduando, para sua realização, o que explica, em alguma medida, o número de declarantes que afirmou a manutenção de vínculo empregatício durante seu bacharelado.

Em relação à continuidade dos estudos após a conclusão do curso de graduação, ficou evidente o empenho dos profissionais na busca por capacitações, tanto no nível de Cursos de Pós-Graduação lato sensu quanto na participação em cursos de capacitações com mais de 40 horas de duração e eventos.

O percentual de enfermeiros que possuem Pósgraduação lato sensu só não é maior devido ao fato das instituições de formação superior em enfermagem de Cuiabá não ofertarem regularmente cursos de especialização(13). Além disso, os cursos oferecidos são, em sua maioria, de iniciativa das escolas privadas que geralmente cobram mensalidades acima das possibilidades da realidade dos salários pagos pelo SUS Cuiabá.

Apesar do número expressivo de enfermeiros que possuem especializações voltadas para a saúde coletiva e da família, é importante ressaltar que uma parcela significativa dos sujeitos não possui qualquer capacitação que colabore para o fortalecimento da Atenção Básica no município, evidenciando a necessidade de investimento, por parte do nível gestor, 
em cursos lato sensu que, de fato, preparem esses profissionais para atuarem na rede de maneira efetiva.

As iniciativas de capacitação visam o aprimoramento profissional, a fim de melhorar a resolutividade dos serviços, contudo, nem sempre essas capacitações atingem seus objetivos com a eficiência esperada, uma vez que fatores como a falta de estímulo financeiro, a falta de um plano de cargos e salários, a longa duração, a ocorrência de cursos fora do horário de serviço e a deficiente infraestrutura, que envolve a falta de organização e as condições do local da capacitação, dificultam a participação de profissionais nessas atividades $^{(15)}$.

A análise do perfil de vínculo e condições de trabalho não possibilitou a constatação da existência de desvio de função, pois $100 \%$ dos profissionais ocupam o cargo de enfermeiro. A carga horária semanal cumprida é de 40 horas para $93,7 \%$ sujeitos e de 30 horas semanais para apenas 6,3\% dos trabalhadores; e o turno de trabalho é integral/dia para 93,7\% dos participantes.

Com relação à função exercida, 96,2\% enfermeiros afirmaram desempenhar funções técnico-assistenciais, aqui compreendidas como o conjunto de atividades desenvolvidas em torno do cuidado ou do seu gerenciamento. E apenas 3,8\% declararam desenvolver funções técnico-administrativas, contudo, vale ressaltar que quase a totalidade dos entrevistados informou que as atividades burocráticas das unidades (que geralmente são de responsabilidade dos enfermeiros) ocupam uma parcela significativa da carga horária de trabalho.

Ainda considerando as condições de trabalho, foi possível identificar o percentual de trabalhadores que possuem mais de um vínculo de trabalho como alternativa de complementação salarial. Dos entrevistados, constatou-se a presença do segundo vínculo profissional para 32,9\% enfermeiros. E destes, apenas $1,3 \%$ declarou possuir o terceiro vínculo. Outro dado que colabora para confirmar a expressiva necessidade de composição de renda por parte dos profissionais estudados é a declaração de $11,4 \%$ sujeitos quanto à atuação em outra atividade remunerada fora da área da saúde.

$\mathrm{Na} A B$, em especial no contexto deste novo modelo de assistência, o processo de trabalho em saúde e enfermagem precisa ter contornos específicos, o que somente é possível com a atuação de profissionais qualificados e com perfil diferenciado, uma vez que a ênfase da assistência não deve estar centrada nos procedimentos técnicos, mas sim na inter-relação equipe/comunidade/família e equipe/equipe ${ }^{(16)}$, característica que requer envolvimento e tempo por parte do enfermeiro para sua operacionalização, o que é dificultado pela existência de outros vínculos trabalhistas.

\section{CONCLUSÃO}

O presente estudo possibilitou a identificação do perfil dos enfermeiros que atuam na $A B$ do município de Cuiabá-MT, gerando informações até então não sistematizadas científica e oficialmente, uma vez que este foi o primeiro estudo realizado no município com tal objetivo.

As informações aqui apresentadas têm potencial significativo para contribuir com o processo de diagnóstico da situação funcional dos enfermeiros da $A B$ e planejamento de ações a serem implementadas pela gestão municipal no sentido de qualificar seu corpo técnico, com vistas à melhor prepará-los para atuação neste nível de atenção, que exige tecnologias de elevada complexidade e baixa densidade.

Os dados levantados apontam para a necessidade de investimentos, por parte dos gestores locais, na educação continuada dos enfermeiros, aliados a esforços voltados para a diminuição do trabalho precário com a efetivação dos profissionais no serviço municipal visando à melhoria das condições laborais. Tais iniciativas, se implementadas em conjunto, podem favorecer a qualificação do trabalhador, uma vez que, por um lado ele estará sendo preparado para atuar de maneira apropriada e, por outro, o profissional ocupará uma posição legal na instituição, pois não haverá o risco eminente de perda do vínculo empregatício, o que se configura como um stress a mais para o trabalhador.

Рага além, é evidente a necessidade de incentivar a capacitação lato sensu orientada para a Atenção Básica, assim como a maior adesão dos enfermeiros aos movimentos políticos, científicos e culturais que se configuram como "nós-críticos" no que se refere à adequação do perfil desses trabalhadores à proposta do SUS para a rede primária de atenção à saúde.

Estudiosos da formação de recursos humanos em saúde afirmam que apesar do movimento da reforma sanitária, na década de 1980, já apontar para a necessidade de investimentos em formação e na gestão 
de recursos humanos no Brasil, as políticas existentes ainda não se mostram efetivas e competentes, de maneira que ainda hoje se percebe o despreparo dos profissionais para atuação na saúde contemplando os princípios do sistema, havendo assim uma discrepância entre a formação e as reais necessidades do SUS ${ }^{(17)}$.

Potencialmente, a apresentação destes resultados pode contribuir com a literatura científica sobre o tema, uma vez que possibilita um aprofundamento da discussão sobre o preparo de enfermeiros para atuação na AB. Para além, os dados podem auxiliar os gestores na elaboração de propostas de melhorias nas condições de trabalho dos enfermeiros, consequentemente,

\section{REFERÊNCIAS}

1. Gil CRR. Atenção primária, atenção básica e saúde da família: sinergias e singularidades do contexto brasileiro. Cad. Saúde Pública. 2006;22(6):1171-181.

2. Melo EM, Paiva L, Alvarez J, Flecha ALD. A organização da Atenção Básica em municípios integrantes do projeto de expansão e consolidação da saúde da família em Mato Grosso, Brasil. Cad. Saúde Pública. 2008;24 Suppl 1:S29-S41.

3. Departamento de Atenção Básica. Secretaria de Atenção à Saúde. Ministério da Saúde. Política Nacional de Atenção Básica. $4^{a}$ ed. Brasília (Brasil): Ministério da Saúde, 2007.

4. Mendonça CS. Saúde da Família, agora mais do que nunca! Ciênc. saúde coletiva. 2009;14 Suppl 1: 1493-1497.

5. Gil CRR. Formação de recursos humanos em saúde da família: paradoxos e perspectivas. Cad. Saúde Pública. 2005;21(2):490-8. 6. Pereira MJB, Fortuna CM, Mishima SM, Almeida MCP, Matumoto S. A enfermagem no Brasil no contexto da força de trabalho em saúde: perfil e legislação. Rev. bras. enferm. 2009;62(5):771-7. 7. Araújo MBS; Rocha PM. Trabalho em equipe: um desafio para a consolidação da estratégia de saúde da família. Ciênc. saúde coletiva. 2007;12(2):455-464.

8. Martins C, Kobayashi RM, Ayoub AC, Leite MMJ. Perfil do enfermeiro e necessidades de desenvolvimento de competência profissional. Texto contexto - enferm. 2006;15(3):472-8. 9. Rocha SMM; Almeida MCP de. O processo de trabalho da enfermagem em saúde coletiva e a interdisciplinaridade. Rev. Latino-Am. Enfermagem. 2000;8(6):96-101.

10. Almeida MCP de; Mishima SM. O desafio do trabalho em equipe na atenção à Saúde da Família: construindo "novas autonomias" no trabalho. Interface - Comunic, saúde, educ. 2001;5(9):150-3. 11. Cotta RMM, Franceschini S do CC, Schott M, Priore SE, Azeredo CM, Dias G. Organização do trabalho e perfil dos profissionais do Programa Saúde da Família: um desafio na reestruturação da atenção básica em saúde. Epidemiol. Serv. Saúde. 2006;15(3):7-18. 12. Secretaria Municipal de Saúde. Diretoria de Atenção Básica. Relatório de Gestão. Cuiabá-MT, 2010.

13. Ribeiro AC. O trabalho do enfermeiro: a relação entre o regulamentado, o dito e o feito, no cotidiano do hospital [thesis]. São Paulo: Escola Paulista de Enfermagem/UNIFESP; 2009. 202p. 14. Departamento de Gestão e da Regulação do Trabalho em Saúde. Secretaria de Gestão do Trabalho e da Educação na Saúde.

Ministério da Saúde. Programa Nacional de Desprecarização do Trabalho no SUS: DesprecarizaSUS: perguntas e respostas. Comitê Nacional Interinstitucional de Desprecarização do Trabalho no SUS. Brasília (Brasil): Ministério da Saúde, 2006.

15. Silva JAM, Ogata MN, Machado MLT. Capacitação dos trabalhadores de saúde na atenção básica: impactos e perspectivas. Rev. Eletr. Enf. [Internet]. [cited 2012 mar 30];9(2):389-01. Available from: http://www.fen.ufg.br/revista/v9/n2/v9n2a08.htm possibilitando a qualificação dos serviços ofertados à população demandante da Rede Básica de Saúde, que passará a ser efetiva e operacionalizada adequadamente.

O presente estudo tem como limitação o fato da população estudada ser pequena, apesar de ter sido composta por todos os enfermeiros da rede básica do município, atuantes em Centros de Saúde e Unidades de Saúde da Família, pois o pequeno número (79 enfermeiros) dificultou a realização de análises estatísticas complexas, o que determinou a utilização da estatística descritiva simples, com realização de inferências.

16. Oliveira RG, Marcon SS. Trabalhar com famílias no Programa de Saúde da Família: a prática do enfermeiro em Maringá-Paraná. Rev Esc Enferm USP [Internet]. [cited 2012 mar 30]; 41(1):65-72. Available from: http://www.ee.usp.br/reeusp/upload/pdf/304.pdf 17. Almeida LPvG; Ferraz CA. Políticas de formação de recursos humanos em saúde e enfermagem. Rev. bras. enferm. 2008;61(1):315 .

Artigo recebido em 29.03.2010.

Aprovado para publicação em 13.03.2012

Artigo publicado em 30.03.2012. 